\title{
Review on Biosurfactant Production and its Application
}

\author{
Priyam Vandana ${ }^{1,2} *$ and Dinesh Singh $^{2}$ \\ ${ }^{1}$ Department of Molecular \& Cellular Engineering, Sam Higginbottom University of \\ Agriculture Technology \& Sciences, Allahabad, U.P., India \\ ${ }^{2}$ Division of Crop Protection, ICAR - Indian Institute of Sugarcane Research, \\ Lucknow, U.P., India \\ *Corresnonding author
}

\section{A B S T R A C T}

Biosurfactants are surface active compounds released by microorganisms. There are several known microbe involve for the production of biosurfactants but exploration of

\section{Keywords}

Biosurfactant Production,

Microbe,

Carbon sources

Article Info

Accepted:

22 July 2018

Available Online:

10 August 2018 potential biosurfactant producer is need of hours to accelerate its economic production for industrial use. These compounds are mainly classified according to their molecular weight, physico-chemical properties and mode of action. They are eco-friendly, easily biodegradable and non-toxic materials. Numerous application of biosurfactants is being practiced with several advantages in laundry cleaning, food processing, cosmetic industry, petroleum, microbial enhance oil recovery, agriculture and medical. It can be produced through use of cheaper, renewable substrates as potential carbon sources come from various industries such as agricultural wastes (sugars, molasses, plant oils, oil wastes, starchy substances and lactic whey), dairy industry whey, distillery wastes, animal fat and oil industries. This leads to greater possibility of economical bio-surfactant production and eco-friendly management of unwanted industrial wastes. Keeping all above merits, the information about the extraction of the different microbial biosurfactants from the cell-free supernatant using the solvent extraction procedure and the qualitative and quantitative analysis has been discussed.

\section{Introduction}

Biosurfactants are low molecular weight surface active compounds widely produced by bacteria, fungi and yeast. The Surfactants term was coined by Antara products in 1950 which covered all products having surface activity, wetting agents, detergents, foaming agents, emulsifiers and dispersants. Surfactants are called as surface active agents, having both polar and non-polar characteristics. This property allows surfactants to lower the surface tension (the attraction between molecules) that causes a cohesive force between a liquid's molecules within the interaction of oil and water. Biosurfactants can be classified according to their microbial origin and chemical structure. Rosenberg and Ron (1999) classified biosurfactant into two categories; high molecular weight molecules (high-mass) and low molecular weight molecules (Low-mass). 
Low-mass surfactants include glycolipids, lipopeptides and phospholipids, whereas highmass surfactants include polymeric and particulate surfactants. Bacteria are the major biosurfactant producers among other microorganisms. The biosurfactant production of microbes or bacteria depends on the fermentation conditions, environmental factors and nutrient availability such as carbon source and nitrogen source.

Biosurfactants had great potential due to its advantages over synthetic surfactants in the fields such as environmental, food, agriculture, biomedical, and other industrial applications. Their large-scale application and production are currently limited due to high cost of production as compared to synthetic surfactant. In this paper, we review the current knowledge and the latest advances in biosurfactant applications and the biotechnological interventions for improving production processes and future potential.

\section{Sources of biosurfactants}

Bacterial biosurfactants: Several bacterial species viz., Pseudomonas aeruginosa, Mycobacterium sp., Arthrobacter sp., are biosurfactant producers and also found to be hydrocarbon degraders.

Fungal biosurfactants: Bacterial biosurfactant production has been explored extensively where as in case of fungus, very fewer fungi are known to produce biosurfactants like Aspergillus, Corynebacterium sp., Dietzia sp., Gordonia sp., Williamsi sp., Tsukamurella sp. (Kuyukina, 2015).

\section{Classification of biosurfactants}

Biosurfactants derived from microbes are classified according to their chemical composition and the microbial source, types of biosurfactants and respective producer microorganisms (Silva et al., 2014). Depending upon the mass the biosurfactant is divided into two groups the low mass biosurfactant includes glycolipid, phospholipid, lipopeptides, lipoproteins and fatty acids and the high mass biosurfactant includes polymeric and particulate surfactant.

Glycolipids: Glycolipids are sugars with long-chain of hydroxyl aliphatic acids or aliphatic acids associated either ester or ether gathering. And the best known glycolipids are sophorolipids, trehalolipids and rhamnolipids.

Rhamnolipids: Rhamnolipids are the glycolipids in which one or two molecules of rhamnose are linked to one or two molecules of hydroxyl decanoic acid. It is the widely studied biosurfactant which are the principal glycolipids produced by Pseudomonas aeruginosa, Pseudomonas sp., Burkholderia sp.

Sophorolipids: These are the glycolipids produced by yeasts and consist of a dimeric carbohydrate sophorose linked to a long-chain hydroxyl fatty acid by glycosidic linkage. Sophorolipids, generally a mixture of at least six to nine different hydrophobic sophorolipids and lactones. Sophorolipid are produced by Torulopsis bombicola, $T$. apícola.

Trehalolipids: It is comprised of disaccharide trehalose connected at six number carbons in benzene ring. Trehalolipids are complex mixture, shift in the size and structure of mycolic corrosive. It affects the quantity of carbon molecules exhibit and the degree of unsaturation. It is characterized by an extremely high structural diversity. And they often occur in a form of complex mixture whose composition varies depending on strain physiology and growth conditions. Trehalolipids produced by Rhodococcus 
erythropolis, Mycobacterium sp., Arthrobacter sp., Corynebacterium, Nocardia, Dietzia, Gordonia, Williamsi, and Tsukamurella sp.

Lipopeptides and lipoproteins: These are higher surface activeness compounds attract special attention among all other biosurfactant. Surfactin is most important lipopeptide biosurfactant among the group. This is the most potential biosurfactant produced by Bacillus subtilis. Comprised of seven amino-corrosive ring structure joined to an unsaturated fat chain.

Apart from this an extraordinary number of cyclic lipopetides including decapeptide antitoxins (gramicidins) and lipopeptide antitoxins (polymyxins) are delivered. These contain a lipid connected to a polypeptide chain. These are:

a. Peptide-lipid- produced by Bacillus licheniformis

b. Viscosin - produced by Pseudomonas fluorescens

c. Serrawettin- produced by Serratia marcenscens

d. Subtilisin- produced by Bacillus subtilis

e. Gramicidin- produced by Bacillus brevis

f. Polymyxin- produced by Bacillus polymyxia

Lichenysin: Several biosurfacants incorporated by Bacillus licheniformis are synergistic to each other and display extraordinary temperature, salt and $\mathrm{pH}$ sensitivity. They are likewise comparative in their auxiliary and physio-synthetic properties to surfactin.

Fatty acids, phospholipids and neutral lipids: Some of the microbes such as yeast and bacteria produce large quantities of fatty acids and phospholipid surfactants during growth and development on n-alkanes. In
Acinetobacter spp. 1-N, phosphatidyl ethanolamine-rich vesicles are delivered which shape optically clear smaller scale emulsions of alkanes in water. These are the basic biosurfactant for therapeutic applications. These are:

a. Fatty acid- produced by Corynebacterium lepus

b. Neutral lipids- produced by Nocardia erythropolis

c. Phospholipids- produced by Thiobacillus thiooxidans

\section{Polymeric biosurfactants}

a. Emulsan- It is a powerful agent, emulsifying hydrocarbons in water, even as low as 0.001 to $0.01 \%$. Emulsion is a poly anionic hetero polysaccharide bioemulsifier produced from Acinetobacter calcoaceticus.

b. Biodispersan- produced by Acinetobacter calcoaceticus.

c. Liposan- produced by Candida lipolytica .

d. Carbohydrate-lipid-protein produced by Pseudomonas fluorescens.

e. Mannan-lipid-protein produced by Candida tropicalis.

Alasan and some other polysaccharide a protein buildings are the best-contemplated polymeric biosurfactants. An isolate of Acinetobacter calcoaceticus RAG-1 integrates an extracellular strong polyanionic amphipathics hetero polysaccharide bioemulsifier.

\section{Particulate biosurfactants}

Vesicles: It is an extracellular film vesicles segment hydrocarbons to from a micro emulsion, which assumes an essential part in alkenes uptake by microbial cells. Vesicles of Acinetobacter sp. comprises of protein, phospholipids and lipopolysaccharide 
(Krishnaswamy et al., 2008; Silva et al., 2014).

\section{Screening of Isolates for Biosurfactant Production}

Drop collapse test: The drop collapse test is an easy and fast procedure to asses a microbe for biosurfactant production. This test does not require any special equipment, only a small volume of microbial sample is required. Drops of oil placed on the slide and then add $10 \mu 1$ of the microbial sample by piercing the drop using micropipette without disturbing the dome shaped of the oil. If the drop collapsed within $1 \mathrm{~min}$ is considered to be positive for the drop collapse test. (Das and Chandran, 2010; Vandana and Peter, 2014b).

Blood agar haemolysis: This is used for priliminary screening of microorganism for the ability to produce biosurfactants. Blood agar plate containing 5\% sheep blood is used for test of haemolytic activity. Positive strains will cause lysis of the blood cells and exhibit a colourless, transparent ring around the colonies. Therefore, those microorganisms which show positive blood haemolysis are considered as biosurfactant producers. The basic principal approach of the followed screening that biosurfactants cause lysis of erythrocytes. The assay also predicts about the surface activity of biosurfactant producing microorganisms (Vandana and Peter, 2014b). As per recommendation the blood agar method as a preliminary screening method which should be supported by other techniques based on surface activity measurements (Mulligan et al., 1984).

Oil displacement activity: This is rapid and easy method to carry out requires a small volume of sample. Due to its high precision, it is applied when the activity and quantity of biosurfactant is low. The biosurfactant producing organism displaces the oil (increase in diameter) and spread in the water. The increase in the diameter of oil is measured due to activity caused by surfactant (Vandana and Peter, 2014c). If biosurfactant is present in the supernatant, the oil is displaced and a clearing zone is developed. The diameter of this clearing zone on the oil surface correlates to surfactant activity. This technique is also known as oil spreading technique.

Emulsification index assay: Emulsification activity gave indication on the presence of biosurfactant. Higher emulsification index indicated a higher emulsification activity of the tested biosurfactant (Vandana and Peter, 2014a).

CTAB agar plate method: The CTAB (Cethyl trimethyl ammonium bromide) agar plate method was developed by Siegmund and Wagner (1991). It is a semi-quantitative assay for the detection of extra cellular glycolipids or other anionic surfactants. The CTAB agar assay is a comfortable screening method, specific for anionic biosurfactants. The disadvantage of this method is that CTAB is harmful as it inhibits the growth of some microbes. Cethyl trimethyl ammonium bromide contains the cationic surfactant. In the process microbes growing on the plate secrets anionic surfactants which form a dark blue, insoluble ion that pair with cethyl trimethyl ammonium bromide and methylene blue (basic dye). Thus, productive colonies are surrounded by dark blue halos.

\section{Effect of composition of culture media on biosurfactant production}

Carbon source: The quantity and quality of the biosurfactant production is influenced by the nature of the carbon source used in the culture medium. Diesel, crude oil, glucose, sucrose, glycerol, mustard oil have been reported to be a good source of carbon substrate for biosurfactant production (Desai and Banat, 1997). 
Nitrogen source: The concentration and nature of nitrogen source also effect the biosurfactant production. Therefore, the biosurfactant production is being regulated by the $\mathrm{C} / \mathrm{N}$ ratio. Nitrogen source plays an important role in the biosurfactant production as protein and enzyme syntheses required for microbial growth depend on the nitrogen source. Different nitrogen compounds have been used for the production of biosurfactants such as yeast extract, malt extracts, meat extract, peptone, urea, ammonium sulphate, ammonium nitrate, and sodium nitrate. Among these, yeast extract is the most commonly used and a good nitrogen source for biosurfactant production.

\section{Biosurfactant production}

Bushnell Haas broth is used as production medium and inoculated with 24-48h old bacterial culture prepared in Nutrient broth medium or 144-168h old fungal culture prepared in potato dextrose and broth medium placed at room temperature in a shaking condition. Allow the inoculated culture to grow under optimum condition for 7-10 days. Centrifuge the culture broth at $10000 \mathrm{rpm}$ for $15 \mathrm{~min}$ to remove the cells in order to obtain clear sterile supernatant (Abouseoud et al., 2007; Vandana and Peter, 2014d).

\section{Biosurfactant recovery}

\section{Cold acetone precipitation method}

In the process three volumes of chilled acetone added to the crude biosurfactant solution and allowed to stand for $10 \mathrm{~h}$ at $4{ }^{\circ} \mathrm{C}$. Precipitate were collected by centrifugation at $10,000 \mathrm{rpm}$ for $20 \mathrm{~min}$ and the resulting pellet is served as partially purified biosurfactant which is further evaporated to dryness to remove residual acetone after that dissolved it in sterile water (Ilori et al., 2005; Vandana and Peter, 2014d).
Acid precipitation method: Biosurfactant can also be precipitated by adjusting $\mathrm{pH}$ of the cell-free broth culture to $2.0 \mathrm{pH}$ using $6 \mathrm{~N}$ $\mathrm{HCl}$ and keeping it at $4{ }^{\circ} \mathrm{C}$ for overnight. Pellet thus precipitated are collected by centrifugation $\left(8000 \mathrm{rpm}\right.$ for $15 \mathrm{~min}$ at $20^{\circ} \mathrm{C}$ ) and dissolved in sterile distilled water. After that $\mathrm{pH}$ is being adjusted at 8.0 by using $1 \mathrm{~N}$ $\mathrm{NaOH}$ for further use (Abouseoud et al., 2008).

Chloroform: methanol precipitation method: The cell free broth was acidified to $\mathrm{pH} 2.0$ with $\mathrm{HCl}$. There after biosurfactant is extracted twice using equal volume of chloroform: methanol (2:1) solution in a separatory funnel (Parhi et al., 2016).

\section{Ammonium sulphate precipitation}

Ammonium sulphate precipitation is used for precipitation of high-molecular weight biosurfactants such as emulsan, biodispersion (protein rich compounds). As per the type of biosurfactant, a different concentration of ammonium sulphate is being used. In case of ammonium sulphate precipitation the rhamnolipid is precipitated by salting out process and the product is further purified by a dialysis procedure and lyophilized (Rosenberg et al., 1979).

\section{Ethanol precipitation}

Like other solvents, ethanol is also used for obtaining crude extract of biosurfactant from the culture supernatant of microbes. Broth culture is centrifuged at $11,000 \mathrm{rpm}$ for 20 $\min$ at $4^{\circ} \mathrm{C}$ and the biosurfactant is precipitated from the supernatant by using cold ethanol. Phetrong et al., (2008) found that precipitation of emulsifier from $A$. calcoaceticus sub sp. anitratus SM7 with ethanol was the most efficient method when compared with other precipitation methods. 


\section{Purification of biosurfactant}

Dialysis: This method is easy and cost effective for the purification of biosurfactant. Dialysis and ultra filtration techniques are widely exploited to enhance the purity of biosurfactant by using seamless cellulose dialysis bags. The collected precipitate samples containing biosurfactant dissolved in 5-10 $\mathrm{ml}$ of sterile distilled water and dialyzed against double distilled water for $48 \mathrm{~h}$ at $10^{\circ} \mathrm{C}$. The dialysate is stored at $4^{\circ} \mathrm{C}$ in an airtight container for further use. Kaplan and Rosenberg (1982) reported production of biosurfactant from A. calcoaceticus BD4 and BD413 which after ammonium sulphate precipitation was dissolved in deionised water and dialyzed in cold distilled water.

Thin layer chromatography: TLC method is used for the preliminary characterization of the biosurfactant. A portion of the crude biosurfactant is separated on a silica gel plate using chloroform: Methanol water (10: 10: $0.5 \mathrm{v} / \mathrm{v} / \mathrm{v})$. The type of biosurfactant is characterized by using developing solvent system with different colour developing reagent. Ninhydrin reagent is used to detect lipopeptide biosurfactant as red spot, produced by biosurfactant (Maheswari and Parveen, 2012).

\section{Characterization of Biosurfactant}

Penetration assay: The penetration assay is a simple, quantitative technique for screening large amounts of potential biosurfactant producing microbial isolates (Maczek et al., 2007). The technique involved that silica gel is entering from hydrophobic phase to the hydrophilic phase in more quickly/faster if biosurfactants are present. This assay is based on the contacting of two insoluble phases which leads to a colour change. The silica gel is entering the hydrophilic phase and the upper phase will change red to cloudy white which results in mixing of the two distinct phases within 15 minutes (Vandana and Peter, 2014a).

Rhamnose test: The presence of carbohydrate groups in the biosurfactant molecule can be assay by this test (Dubois et al., 1956). A mixture of $0.5 \mathrm{ml}$ of surfactant with $0.5 \mathrm{ml}$ of $5 \%$ phenol and $2.5 \mathrm{ml}$ of sulphuric acid is being incubation for $15 \mathrm{~min}$ before measuring absorbance at $490 \mathrm{~nm}$ through calorimeter.

Biochemical characterization: Chemical composition of the biosurfactant can be analysed by different methods discussed under the topic. Carbohydrate content of the biosurfactant can be determined by anthrone reagent method using $620 \mathrm{~nm}$ (Spiro, 1966) using D-glucose as standard. Protein content determined by the Lowery et al., (1951) using bovine serum albumin as a standard. Lipid content can be estimated adopting the methodology developed by Folch and his coworkers in 1956.

Nuclear magnetic resonance: NMR provides information regarding the functional groups about the position of linkages within the lipid and carbohydrate molecules. This is based on transitions in atoms with a magnetic moment when an external magnetic field is applied. Glycolipid biosurfactant was carried out with the help of NMR methodology in year 2009 by Smyth and his co-workers.

\section{Fourier transform infrared spectroscopy} (FT-IR): Fourier transform infrared spectroscopy (FT-IR) analysis can be used to elucidate some components of an unknown mixture to identify the types of chemical bonds (functional groups). In the process one milligram of partially purified biosurfactant dried in freeze dryer was ground with $100 \mathrm{mg}$ of potassium bromide and pressed for $30 \mathrm{sec}$ to obtain translucent pellets. And then analyze in a FTIR (Perkin-Elmer Spectrum RX1, Shelton, Connecticut), device with the 
spectrum ranging from $450-4000 \mathrm{~cm}-1$ at a resolution of $4 \mathrm{~cm}^{-1}$ (Elazzazy et al., 2015).

Fast atom bombardment- mass spectroscopy (FAB-MS): It is a soft ionization method, requires a direct insertion probe for sample introduction. A high energy beam of xenon atoms or caesium ions is used to stammer the sample and the matrix from the probe's surface. The matrix (m-nitro benzyl alcohol) dissolves the sample and helps in desorption, ionization. Biosurfactant sample is dissolved in methanol and is mixed with matrix and then used for analysis. Rhamnolipid mixtures using FAB-MS method was identified by Manso Pajarron et al., (1993).

Chemical analysis using gas chromatography (GC) and mass spectroscopy (MS): A gas chromatography column and a mass interface are being used in this process. The process is supported with software MS facility which acts as a gas chromatography. Mass spectroscopy measures the molecular weight of the biosurfactant compound. Separate peaks arise in the gas chromatography column and enter in Mass spectroscopy. GC coupled with MS is the most sensitive method for the quantification and identification of glycolipids type of biosurfactant. High amounts of lipid are associated with high molecular weight biosurfactant. For the analysis of biosurfactant sample in a GC-MS device, the sample needs hydrolytic cleavage between the peptide/protein or carbohydrate/lipid portions present in the biosurfactant. GC-MS results are analysed by derivatization of fatty acid chains to fatty acid methyl esters (FAME) and further conversion to trimethylsilyl (TMS) derivatives (Yakimov et al., 1995).

High pressure liquid chromatography (HPLC): HPLC is used generally used for the separation of lipopeptide biosurfactant
(Aguilar, 2004). Initially this method was used to free rhamnose from rhamnolipid (Siegmund and Wagner, 1991).

HPLC consists of three phases that is stationary phase, mobile phase and a detector. The mobile phase carries the sample solution injected through the injector port. The stationary phase is a solid medium over which the mobile phase continuously flow the components of sample solution. The sample is treated with trifluro acetic acid (TFA) and further centrifuged for the removal of solid particles.

Glycolipids biosurfactant can be separated and identified successively when a HPLC device coupled with mass spectrometry or evaporative light scattering detector (ELSD). Technique separation of various components from the sample is being separated with the principals based on their polarity. The separated products can be detected, and analyze the structure of each moiety on the fractions collected for individual peaks. HPLC along with Mass Spectroscopy facility are essential for providing the molecular mass of each fraction.

\section{Characterization of foaming and emulsifying properties of biosurfactant}

The foam will be produced by hand shaking of crude biosurfactant solution. The stability of the foam could be monitored by observing it for $2 \mathrm{~h}$. The ability of the biosurfactant to emulsify can be determined by some liquid hydrocarbons, such as mustard oil, olive oil, soyabean oil, coconut oil and palm oil.

The sterile biosurfactant $(2 \mathrm{ml})$ and the substrate $(2 \mathrm{ml})$ placed together in a test tube and the content was vortexed at high speed for $2 \mathrm{~min}$ and left undisturbed for $24 \mathrm{~h}$ (Cooper and Goldenberg, 1987). 
Determination of Stability of Emulsification Property of Biosurfactant (Vandana and Peter, 2014a; Vandana and Peter, 2014d).

The emulsification capability of biosurfactant is calculated by index $\left(\mathrm{E}_{24}\right)$. It is determined by dividing the measured height of emulsion layer by the mixture's total height $(\mathrm{cm})$ and multiplying by 100 .

Effect of different hydrocarbons: Effect of different hydrocarbons on emulsification index can be determined by performing emulsification activity of the biosurfactants by adding different oils such as mustard oil, til oil, coconut oil, palm oil, almond oil, sunflower oil, olive oil and soyabaen oil to the aqueous solution of the biosurfactant and vortexed at high speed for $2 \mathrm{~min}$. Emulsification index $\mathrm{E}_{24}$ is calculated at different time intervals.

Effect of salt concentrations: To observe the effect of salt concentrations on emulsification index, emulsification activity of the biosurfactants was performed by adding $2 \mathrm{ml}$ of the mustard oil to $2 \mathrm{ml}$ of the aqueous solution of the partially purified biosurfactant and vortexed at high speed for $2 \mathrm{~min}$. The emulsification stability can be determined at varying $\mathrm{NaCl}$ concentrations and emulsification index $E_{24}$ is calculated.

Effect of pH: Effect of $\mathrm{pH}$ on emulsification index can be determined through emulsification activity of the biosurfactants. It is performed by adding $2 \mathrm{ml}$ of the mustard oil to $2 \mathrm{ml}$ of the aqueous solution of the biosurfactant and vortexed at high speed for 2 min. Calculate the emulsification index $\mathrm{E}_{24}$ at different $\mathrm{pH}$.

Effect of temperature: Temperature plays a major role in emulsification activity of biosurfactant. To observe the effect of temperature on emulsification index, emulsification activity of the biosurfactants was performed by adding $2 \mathrm{ml}$ of the mustard oil to $2 \mathrm{ml}$ of the aqueous solution of the biosurfactant and vortexed at high speed for 2 min. Calculate the emulsification index $\mathrm{E}_{24}$ at different temperature up to $100^{\circ} \mathrm{C}$.

\section{Substrates used for commercial biosurfactant production}

Agricultural wastes: Aqueous extracts of the agro-wastes such as banana peels, orange peels, potato peels and bagasse can be prepared by using the procedure described by Kulkarni et al., (2015). Stock solutions of agro-wastes will be prepared by autoclaving $10 \%(\mathrm{w} / \mathrm{v})$ from the suspensions of each dried waste. Further the extract will be filtered through Whatman filter paper no.1 or muslin cloth and the obtained filtrate will be reautoclaved for the production of biosurfactant.

Dairy industry whey: Curd whey requires processing to remove casein content by method given by Nitschke et al., (2010). Curd whey should be neutralized with $5 \mathrm{~N} \mathrm{NaOH}$ followed by steaming for $10 \mathrm{~min}$.

This process allows casein to settles at the bottom in the form of sodium caseinate and the supernatant is removed as partially deproteinised whey and filtered through membrane filter before sterilization at $15 \mathrm{lbs}$.

Industrial wastes: Different types of no-cost industrial wastes is being used as growth medium for biosurfactant producing isolates to minimize the cost of fermentation medium. In the experiment conducted by Martins and Martins, (2018) Corynebacterium aquaticum showed efficient biosurfactant production by using fish and bagasse residues as carbon source. Corynebacterium aquaticum have desired potential to produce an effective biosurfactant by using industrial wastes. 
Distillery waste, fruit processing waste and sugar industry effluent can also be used for the biosurfactant production.

Vegetable oils: It is a common medium used in large quantities for biosurfactant production. It can act as an effective and inexpensive raw material for biosurfactant production. Out of different vegetable oil, mustard oil has been used by Vandana and Peter (2014a) for biosurfactant production.

\section{Application of Biosurfactant}

\section{Applications in commercial Laundry} detergents: Surfactants, which is an important component used in commercial laundry detergents is exerting toxicity to fresh water living organisms due to its chemical synthesization. Public awareness about the environmental pollution through chemical surfactants is increasing day by day. It has stimulated the search for natural substitutes of chemical surfactants in laundry detergents which are eco friendly in nature. Heating of biosurfactants such as Cyclic Lipopeptide (CLP), at high temperature does not result in any loss of their surface-active property as they are stable over a wide $\mathrm{pH}$ range (7.012.0) and also at high temperatures (Mukherjee, 2007). They had a capability of good emulsion formation with vegetable oils and also demonstrated excellent stability and compatibility with commercial laundry detergents favouring their inclusion in laundry detergents formulation (Das and Mukherjee, 2007).

Application in food processing industry: Biosurfactants play an important role as food formulation ingredient and anti-adhesive agents. Due to their ability to decrease the surface and interfacial tension, they are used as food formulation ingredient to promote the formation and stabilization of emulsion. It is also used to control the agglomeration of fat globules, improve texture, stabilize aerated systems and shelf life of starch containing products, modify rheological properties of wheat dough and improve consistency and texture of fat based products (Krishnaswamy et al., 2008).

Application in cosmetic industry: In the cosmetic industry it is proposed to replace chemically synthesized surfactants completely through biosurfactant because it also has the properties such as foaming, water binding capacity, emulsification, spreading and wetting properties effect on viscosity and product consistency. Biosurfactants are used as emulsifiers, foaming agents, cleansers, solubilizers, antimicrobial agents, wetting agents, mediators of enzyme action, bath products, in insect repellents, acne pads, anti dandruff products, baby products, toothpaste, contact lens solutions, mascara, lipsticks and dentine cleansers (Gharaei-Fathabad, 2011).

Application in petroleum: Bioemulsifiers and biosurfactants are the novel group of molecules. It is the most powerful and versatile by product among modern microbial technology. It can be exploited effectively in fields such as enzymes and biocatalysts for petroleum upgrading, bio fouling degradation and biocorrosion of hydrocarbons within oil reservoirs, (Perfumo et al., 2010). Biosurfactants also plays an important role in petroleum extraction, upgrading and refining and petrochemical manufacturing.

Application in microbial enhanced oil recovery: In running time biosurfactants are widely used in oil recovery. Microbial enhanced oil recovery includes use of microbes and the exploitation of their metabolic processes to increase production of oil from marginally producing reservoirs. The mechanism which is responsible for oil release is acidification of the solid phase. Certain microbes, such as Pseudomonas 
aeruginosa, Bacillus subtilis and Torulopsis bombicola have been reported to utilize hydrocarbons and crude oil as a sole carbon sources and can also be used for oil spill clean-ups (Das and Mukherjee, 2007).

Applications in agriculture: The biosurfactants produced by microorganisms have more advantages as compared to the chemically synthesized surfactants in the field of agriculture. The biosurfactants have antimicrobial property can be used widely in the areas related to agriculture for the management of different disease caused by microbes. It can also be utilized for biodegradation of pollutants to improve the quality of the soil. Several bacteria produce lipopeptide biosurfactants which exhibits insecticidal activity against fruit fly Drosophila melanogaster and hence can be used as biopesticide (Mulligan, 2005). The emergence of pesticide resistant insect populations as well as rising prices of new chemical pesticides has stimulated the use of biosurfactant as a new eco-friendly vector control tools.

Applications in medical: Some of the biosurfactants have solid antibacterial, antifungal and antivirus action. The biosurfactant produced by marine $B$. circulans had a powerful antimicrobial action against Gram negative pathogens, Gram positive pathogens and Semi pathogenic microbial strains including MDR strain (Kugler et al., 2015). Biosufractant produced by Pseudomonas fluorescens and Pseudomonas aeruginosa showed antimicrobial properties against some of the bacterial isolates causing diseases in humans (Vandana and Peter, 2014d).

\section{Advantages of biosurfactant}

Biosurfactants have several advantages when compared to chemical surfactant.
Use of low cost substrates: Biosurfactants are largely produced from raw materials available at cheap price. Hydrocarbons, carbohydrates and /or lipids, can be used separately or in combination with each other as a carbon source (Kosaric, 2001).

Specificity: Biosurfactant producing microbes are very specific with their substrate. Apart from this specific type of biosurfactant is being produced from a specific microbe such as surfactin is produced from Bacillus subtilis.

Eco-friendly: Biodegradability is a very important issue in relation to environmental pollution. Biosurfactant do not create much problem to the environment as they are easily biodegraded there after reduces pollution. It is suited for environmental applications such as bioremediation and dispersion of oil spills (Mulligan, 2005).

Physical factors: Environmental factors such as $\mathrm{pH}$, temperature and ionic strength cannot affect most of the biosurfactants. Bacillus licheniformis strain produces Lichenysin which was not affected by a $\mathrm{pH}$ range of 4-59.0 , temperature ranges of up to $50^{\circ} \mathrm{C}, \mathrm{NaCl}$ concentration of $50 \mathrm{~g} / \mathrm{l}$ and $\mathrm{Ca}$ concentration of 25g/l (Krishnaswamy et al., 2008).

Low toxicity: Chemically derived surfactants possess higher toxicity than the biosurfactant. It was also reported that biosurfactants showed higher EC 50 values (effective concentration to decrease $50 \%$ of test population) than synthetic surfactant (Desai and Banat, 1997).

Biodegradability: Biosurfactants are biodegradable in nature and can be easily degraded in nature (Mohan et al., 2006). It can be broken down within short span of time by bacteria, fungi or other simple organisms into more basic components. 
Biocompatibility: Biosurfactants are biocompatible in nature (Rosenberg and Ron, 1999). Living organisms are able to perform their physiological activity as per their potential. When these biological surfactants interact with living organisms they do not change the bioactivity of the organisms. Due to this property, they have their application in pharmaceuticals, cosmetics and as functional food additives.

\section{Disadvantages of biosurfactant}

Despite of having so many advantages, there are certain disadvantages also (Rahman and Gakpe, 2008):

Maintenance of aseptic condition: Sterilized medium is essential for the biosurfactant production therefore large scale production of biosurfactants is quite difficult and expensive process.

Poor yield from raw substrate material: During the process of biosurfactant production raw substrates are resulting less yield as compared to the processed substrate materials. Raw substrate takes more time for the production of biosurfactant.

Problems in product recovery and purification: The acquisition of products with a high degree of purity is difficult because of several consecutive purification steps for the metabolic broth is required.

Problem in control of the process like foaming: In the process to increase the productivity, formation of foam is creating complication. To overcome the problem, it requires the use of a diluted medium.

Lack of knowledge regarding the biosurfactant producing microbes: Superproducing microbial species are very rare. Known microbial species are not capable of producing large amount of surfactant yields and it also requires a complex culture medium. In this context, exploration of potential microorganisms for biosurfactant production is today's need. The regulation of biosurfactant synthesis is not fully understood till now whether, these biomolecules may be produced as secondary metabolites or in association with microbial growth.

In conclusion, it has been established that the biosurfactants are eco friendly product and suitable for the use in medical applications like health care and treatment of diseases. It is very good exploited for biodegradation of oils, controlling environmental pollution, oil fields, cosmetic industry, oil industry, removal of oil pollutions, applications in agriculture and agrochemical industries. It can be easily produced by using cheap agro industrial wastes and use of oil as substrates. Biosurfactant production can be realized from waste oils such as edible or motor oil as a carbon source. Bacterial consortia can be more efficient for the production of biosurfactant as compared to the single microbe. As these biosurfactants have antimicrobial property it can be used as biocontrol agents also. There is a need of hours to explore the potential microbes for its production, standardization of best substrate and appropriate methodology. Such studies will help for replacing harsh chemical surfactants with the green ones. The agricultural wastes can also be used for the biosurfactant production. The emulsifying activity of the biosurfactant is another branch having full scope that they can be used as emulsion forming agents for hydrocarbons and oils giving stable emulsions. Despite of having so many advantages of biosurfactant, its industrial use is still limited due to the involvement of high cost in its production process. Biosurfactants have led considerable interest for present and future application due to non-toxic and eco-friendly nature. 


\section{References}

Abouseoud, M., Maachi, R., Amrane, A., Boudergua, S. and Nabia, A. 2007. Evaluation of different carbon and nitrogen sources in production of biosurfactant by Pseudomonas fluorescens. Journal of Microbiology and Biotechnology. 223:143-151.

Abouseoud, M., Yataghene, A., Amrane, A. and Maachi, R. 2008. Biosurfactant production by free and alginate entrapped cells of Pseudomona fluorescens. Journal of Industrial Microbiology and Biotechnology. 35:1303-1308.

Aguilar, M. I. 2004. Methods in molecular biology: HPLC of peptides and proteins; Methods and Protocols Vol. 251. Humana Press. Totowa, New Jersey 0751.

Cooper, D. G. and Goldenberg, B. G. 1987. Surface active agents from two Bacillus sp. Journal of Applied Environmental Microbiology. 53:224229.

Das, N. and Chandran, P. 2010. Microbial Degradation of Petroleum Hydrocarbon Contaminants: An Overview. Biotechnology Research International. 2011:1-13.

Das, K. and Mukherjee, A. K. 2007. Crude petroleum-oil biodegradation efficiency of Bacillus subtilis and Pseudomonas aeruginosa strains isolated from petroleum oil contaminated soil from north-east India. Bioresource Technology. 98:1339-1345.

Desai, J. D., Banat, I. M. 1997. Microbial production of surfactants and their commercial potential. Microbiology and Molecular Biology Reviews. 61:47- 64 .

Dubois, M., Gills, K. A., Hamilton, J. K., Rebers, P. A. and Smith, F. 1956.
Colorimetric Method for Determination of Sugars and Related Substances. Analytical chemistry. 28:350-360.

Elazzazy, A. M., Abdelmoneim, T. S. and Almaghrabi, O. A. 2015. Isolation and characterization of biosurfactant production under extreme environmental conditions by alkalihalo-thermophilic bacteria from Saudi Arabia. Saudi Journal of Biological Science. 22(4):466-475.

Folch, M., Lees, J. M., and Stanly, H. S. 1956. A simple method for the isolation and quantification of total lipids from animal tissues. Journal of Biological Chemistry. 226:497-509.

Gharaei-Fathabad, E. 2011. Biosurfactants in pharmaceutical industry: A MiniReview. American Journal of Drug Discovering and Development. 1:5869.

Ilori, M. O., Amobi, C. J. and Odocha, A. C. 2005. Factors affecting Biosurfactant production by oil degrading Aeromonas spp. isolated from a tropical environment. Chemosphere. 6:110-116.

Kaplan, N. and Rosenberg, E. 1982. Exopolysaccharide distribution of and bioemulsifier production by Acinetobacter calcoaceticus BD4 and BD413. Applied and Environmental Microbiology. 44:1335-1341.

Krishnaswamy, M., Subbuchettiar, G., Ravi, T. K. and Panchaksharam, S. 2008. Biosurfactants properties, commercial production and application. Current Science. 94:736-747.

Kosaric, N. 2001. Biosurfactants and their Applications for Soil Bioremediation. Food Technology and Biotechnology. 39:295-304.

Kugler, J. H., Le Roes-Hill, M., Syldatk, C. and Hausmann, R. 2015. Surfactants tailored by the class Actinobacteria. 
Frontiers of Microbiology. 6:212.

Kulkarni, S. O., Kanekar, P. P., Jog, J. P., Sarnaik, S. S. and Nilegaonkar, S. S. 2015. Production of copolymer, poly (hydroxybutyrate-co-hydroxyvalerate) by Halomonas campisalis MCM B1027 using agro-wastes. International Journal of Biological Macromolecules. 72:784-789.

Kuyukina, M. S., Ivshina, I. B., Baeva, T. A., Kochina, O. A., Gein, S. V. and Chereshnev, V. A. 2015. ReviewTrehalolipid biosurfactants from nonpathogenic Rhodococcus, Actinobacteria with diverse immune modulatory activities. New Biotechnology. 32(6):559-568.

Lowry, O. H., Rosebrough, N. J., Farr, A. L. and Randall, R. J. 1951. Protein measurement with the folin phenol reagent. Journal of Biological Chemistry. 193: 265-275.

Maczek, J., Junne S. and Gotz P. 2007. Examining biosurfactant producing bacteria-an example for an automated search for natural compounds. Application Note CyBio AG.

Maheswari, N. U. and Parveen, 1. F. 2012. Comparative study of biosurfactant by using Bacillus licheniformis and Trichoderma viride from paper waste contaminated soil. International Journal of Chemical Sciences. 10(3):1687-1697.

Manso, P. A., De Koster, C. G., Heerma, W., Schmidt, M. and Haverkamp, J. 1993. Structure identification of natural rhamnolipid mixtures by fast atom bombardment tandem mass spectrometry. Glycoconjugate Journal. 10:219-226.

Martins, P. C. and Martins, V. G. 2018. Biosurfactant production from industrial wastes with potential remove of insoluble paint. International Biodeteoriation and
Biodegradation. 127:10-16.

Mohan, P. K., Nakhla, G. and Yanful, E. K. 2006. Biokinetics of biodegradability of surfactants under aerobic, anoxic and anaerobic conditions. Water Research. 40: 533-540.

Mukherjee, A. K. 2007. Potential application of cyclic lipopeptide biosurfactants produced by Bacillus subtilis strains in laundry detergent formulations. Letters in Applied Microbiology. 45(3):330-335.

Mulligan, C. N. 2005. Environmental applications for biosurfactants. Environmental Pollution. 133(2):18398.

Mulligan, C., Cooper, D. and Neufeld, R. 1984. Selection of microbes producing biosurfactants in media without hydrocarbons. Journal of Fermentation Technology. 62(4):311-314.

Nitschke, M., Costa, S. G., Contiero, J. 2010. Structure and application of a rhamnolipid surfactant produced in soybean oil waste. Applied Biochemistry and Biotechnology. 160:2066-2074.

Parhi, P., Jadhav, V. V. and Bhadekar, R. 2016. Increase in production of biosurfactant from Oceanobacillus sp. BRI 10 using low cost substrates. Songklanakarin Journal of Science and Technology. 38(2):207-211.

Perfumo, A., Rancich, I. and Banat I. M. 2010. Possibility and challenges for biosurfactant uses in petroleum industry. Advances in Experimental Medicine and Biology. 672:135-145.

Phetrong, K., Kittikun, H. and Maneerat, A. S. 2008. Production and characterization of bioemulsifier from a marine bacterium, Acinetobacter calcoaceticus sub sp. Anitratus SM7. Songklanakarin Journal of Science and Technology. 30(3): 297-305.

Rahman, K. S. M. and Gakpe, E. 2008. 
Production, Characterization and applications of biosurfactants- a review. Biotechnology. 7:360-370.

Rosenberg, E. and Ron, E. Z. 1999. High and low molecular mass microbial surfactants. Applied Microbiology and Biotechnology. 52(2):154-162.

Rosenberg, E., Zuckerberg, A., Rubinovitz, C. and Gutnick, D. L. 1979. Emulsifier of Arthrobacter RAG-1: isolation and emulsifying properties. Applied and Environmental Microbiology. 37:402408.

Siegmund, I. and Wagner, F. 1991. New method for detecting rhamnolipids excreted by Pseudomonas spp. during growth on mineral agar. Biotechnolgy Techiques. 5: 265-268.

Silva, R. F. S., Almeida, D. G., Rufino, R. D., Luna, J. M., Santos, V. A. and Sarubbo, L. A. 2014. Applications of Biosurfactants in the Petroleum Industry and the Remediation of Oil Spills. International Journal of Molecular Science. 15:12523-12542.

Smyth, T. J. P., Perfumo, A., Marchant, R. and Banat, I. M. 2009. Isolation and analysis of low molecular weight microbial glycolipids: Microbiology of hydrocarbons, oils, lipids, and derived compounds. In: Kenneth N. Timmis ed. Springer, UK (in press).

Spiro, R. G. 1996. Analysis of sugar found in glycoproteins. Methods in Enzymology. 8:7-9.

Vandana, P. and Peter, J. K. 2014a.
Biochemical characterization and antimicrobial properties of ramnolipids produced by Pseudomonas fluorescens using mustard oil as carbon source. International Journal of Current Research. 6(10):9069-9074.

Vandana, P. and Peter, J. K. 2014b. Production, partial purification and characterization of biosurfactant from Pseudomonas fluorescens. International Journal of Advanced Technology in Engineering and Science. 2(7):258-264.

Vandana, P. and Peter, J. K. 2014c. Partial purification and characterization of biosurfactant from Pseudomonas aeruginosa. International Journal of Engineering Sciences and Research Technology. 3(9):45-50.

Vandana, P. and Peter, J. K. 2014d. Determination of antimicrobial activity and production of biosurfactant by Pseudomonas aeruginosa. International Journal of Engineering Sciences and Research Technology. 3(10):254-260.

Yakimov, M. M., Timmis, K. N., Wray, V. and Fredrickson, H. L. 1995. Characterization of a new lipopeptide surfactant produced by thermotolerant and halotolerant subsurface Bacillus licheniformis BAS50. Applied and Environmental Microbiology. 61: 1706-1713.

\section{How to cite this article:}

Priyam Vandana and Dinesh Singh. 2018. Review on Biosurfactant Production and its Application. Int.J.Curr.Microbiol.App.Sci. 7(08): 4228-4241. doi: https://doi.org/10.20546/ijcmas.2018.708.443 